\title{
How do Teachers Treat the Students with Learning Difficulties-An Analysis based on Humanistic Theory of Carl Rogers
}

\author{
Pengfei Yin \\ School of Electronic Information, Qingdao University, Qingdao 266071, China \\ yinpengfeiii@163.com
}

\begin{abstract}
Keywords: transformation of students with learning difficulties, non-directive instruction, significant learning.
\end{abstract}

\begin{abstract}
It is a popular phenomenon that the students with learning difficulties are commonly found throughout the schools at all stages. Students with learning difficulties, the group with normal intelligence but terrible performance in school, even behind the average level, have a lot of potential that have not been developed. As such, those students who have difficulties in learning can be educated and transformed into normal ones by using some specific teaching methods by teachers. Based on Rogers' humanistic theory, the author analyzes the causes of students with learning difficulties from different psychological factors by interviewing some teachers with rich management experienced and students with learning difficulties in a county high school. Good relationship between teachers and students is the entry point of this article and there is four aspects should be considered by teachers: sincerity, unconditional and positive attention, empathy, and cultivation of learning interests. As a result, it can provide a safe and free learning atmosphere for students. If the students with learning difficulties study under such atmosphere, they will reach self-development finally. In addition, the difficulties in the process of transformation are also reflected in above interviews. Therefore, a further solution is needed to be set out in future studies.
\end{abstract}

\section{Introduction}

The American humanism educationist Carl Ransom Rogers pointed out, "The promotion factors of student learning are not entirely determined by educational skills, professional knowledge, lesson plans, auxiliary appliance, programmed instruction, presentation or demonstration, and various books, which are sometimes be used as important resources for student learning, but the interpersonal relationship between students and facilitators(educators) is the most significant factor in promoting student learning."[1]. A good teacher-student relationship enables both students and teachers to be in a positive atmosphere so that all they can fully exert their subjective initiative, improving learning effect qualitatively. Thus it can be seen that a good teacher-student relationship is particularly important for the transformation of poor students.

The problem is that what a good teacher-student relationship looks like? In Rogers' idea about education, the relationship between teachers and students should be presented as following characteristics: acceptance and understanding, cooperation and dialogue, equality and democracy. [2] In other words, sincere attitude is the key that should be considered by teachers when they teach their students. Standing the point of student's view, teachers should express acceptance and understanding of problems that arise in students. As facilitators of student learning, teachers should actively cooperate, communicate with students and exchange their opinions. Equal communication between teachers and students is needed. A psychological environment full of free, democracy and philanthropy should be provided to students.

The author conducts a number of interviews with students who have difficulties in their study and two teachers who have their own specific strategies for managing those students. According to the interview records consolidated by author, the article will carry out the discussion from the following several aspects. 


\section{The Course of Students with Learning Difficulties}

Students with learning difficulties referred to those with normal intelligence but poor performance in school. Influenced by psychological factors, their performance in grade and morality was temporarily below average. However, these students had the possibility to be transformed into normal ones [3]. From the point can be seen, students with learning difficulties can be transformed. The following interviews show that the main reason for appearance of students who have difficulties in their learning is the lack of learning interest and rare communication with teachers. Therefore, teachers should provide a safe and free psychological atmosphere for students with learning difficulties and go into their emotional world as much as possible. This is the reflection of Rogers' non-directive instruction that emphasis should be placed on the thoughts and emotions of students. As a result, students can study freely.

During the interviews, it is discovered that not all the students with learning difficulties are poor in all subjects, but they tend to go overboard on one or some subjects: For some subjects, they can't pass their exam. Meanwhile, they can even achieve excellence in some other subjects. Therefore, each subject as a research object is applied in this article for discussion. When asked to the subject students good at, the author find out that the interviews have a high academic record in the subject they interested in. The greater the interest in learning, the higher the score is. Therefore, the most important reason for students who have learning difficulties in a subject is the lack of interest in it.

"I' $m$ better at Chinese thanks to my good ability in comprehension and reading. I have always liked to read books, especially the novels and prose written in the Republic of China." (good student A)

"Math has been my favorite subject since I was a child. For me, math is not so hard and I have always been very good at it."(A student with learning difficulties)

It is clear to say that the love for a subject of students is their powerful intrinsic impetus for study. Due to the love for a subject, students' curiosity will be aroused as they find the interesting phenomenon in the subject area. Driven by their curiosity, students will actively explore and gradually develop their own learning methods, and ultimately achieve outstanding results in the subject. This coincides with the idea of significant and free learning of Rogers. He advocated significant learning which combined study with the aspirations and interests of students by regarding students' experience growth as its center and considering students' spontaneity and initiative as study impetus. The significant and free learning concept of Rogers emphasized that a person (both emotional and cognitive) should be totally involved in learning activities, and that the feeling of discovery, acquisition, mastery, and comprehension should come from students themselves. [4]

\subsection{Self-Abandonment Because of Poor Academic Performance for Long Time.}

The common phenomenon among many students with learning difficulties is that they don't study hard or find the way to study because of the lack of interest in textbook contents from middle, even primary school. With the passage of time, students have tended to a cognition that they can't do well in studying due to the increased times of unsatisfactory grades. As a result, they become more and more self-contemptuous. If there is no timely communication with teachers or parents, and places where negative emotions can be released, students will tend to lose confidence and give up on themselves with all sorts of puzzles and worries accumulating.

"I can't find the reason why I am always absent-minded in math class."'(Student B with learning difficulties)

'I'm sick of junior English. It's so hard to understand, and the teacher gives us a fast lesson. Usually, I haven't understood a knowledge point but the teacher has begun to teach another. The only tip my teacher tell to learn English is to do more practices and often to check the dictionary."'(Student $\mathrm{C}$ with learning difficulties)

"Junior math is more difficult to learn. I'm sometimes distracted and can't catch the teacher's pace in the class. My grade had an improvement after attending supplementary courses. However, it went down again when the courses ended."(Student D with learning difficulties)

It can be seen that the difficulty in learning for those senior high school students mentioned above is due to the fact that many knowledge are missed during their junior school, even primary school 
period, resulting a greater pressure for them to learn and keep up with the process of course when they enter high school. During this time, the learning enthusiasm and confidence of students with learning difficulties have gradually faded away. Meanwhile, this part of students with learning difficulties is resistant to communicate with their teachers. Therefore, they are reluctant to communicate with the teacher actively. At this point, if the students does not get promptly inspiration from their teacher, they will be likely to give up the discipline at the end. Therefore, suggestions provided by warm and sincere teachers are needed for helping students get out of their troubles in learning.

\subsection{Hard to Finish Tasks Assigned by Teachers on Time Due to Poor Self-Control.}

Students with poor self-control are too lazy to study. They are unwilling to work hard on these subjects. Without teachers' urge and supervision, it is difficult for students with poor self-control to actively complete corresponding learning goals.

"My teacher criticizes me for not reciting the texts he asks us. I can't concentrate on my text books and always want to go out play when I just recite the first half. I can't do it by myself. Only teacher supervises me by my side can I recite it" (Student C with learning difficulties)

"It's not so stressful to learn at holiday. So it's better to be more efficient at school."(Student D with learning difficulties)

"Will you listen carefully if the teacher explains these knowledge points you don't understand again?" "Em... I don't know."(Student $\mathrm{C}$ with learning difficulties)

Rogers believed that one of the important factors of significant learning was that learning is spontaneous. It was possible that certain motivations and incentives could be found in the outside world, but the feeling of discovery, acquisition, mastery, and comprehension should come from students themselves. [5] For these students with learning difficulties who are not interested in learning in this part, they want to improve their grades just because of the academic pressure and the expectation of parents, which is not enough to push them to explore knowledge. That is also a violation for the significant learning concept advocated by Rogers. As a result, these students ultimately can't find the best learning method that is truly suitable for them.

\subsection{Learning Is Just Used to Deal with Exam.}

In the interviews, we find that some of the students who are struggling to learn merely mechanically learn and simply deal with the exam. For students with learning difficulties, they feel that learning is like a task assigned by teachers that must be completed. Their learning activities need to be monitored and spurred by others.

"... (Learning) for a better life. For me, the knowledge I currently learning is useless. What I do is just to deal with college entrance examination. Personally, I prefer to study more entrepreneurial skills because that's my way I want to go in the future."(Student D with learning difficulties)

From the above interviews, it can be seen that learning methods or concepts adopted by students with difficulties in learning are not the significant learning advocated by Rogers. In their opinion, the purpose of study is just to cope with exams. Therefore, students are not able to actively study. A large part of contents of their current learning are regarded as no personal significance to themselves. This is what Rogers considered to be "insignificant learning" that involved only the mind but no emotion. The reason for this is that the comprehension ability and logical thinking ability of students appear to have no any improvement under current subject education, at least for these poor students. They can't find a connection between the contents they study and their needs. The needs can't be satisfied and the knowledge they want to study can't be provided for them under such learning way. Therefore, the learning way of students with learning difficulties not only will not result in the accumulation of knowledge, but also will not lead to a comprehensive development in their behavior, attitude and personality.

\section{How Do Teachers Treat Students with Learning Difficulties?}

We can adopt Rogers' "Non-directive instruction" strategy to deal with students with learning difficulties, which takes self-actualization as the guiding ideology. With regard to "self", Rogers made 
the following definition: "The self includes the individual who perceives the whole of his organism and all the sensations he experiences and its relation with other sensations in the environment and to the entire outer world."[5] According to Rogers' humanistic theory, we can see that the key to the self-actualization is to create a harmonious psychological atmosphere where a sincere, trustful and understandable interpersonal relationships can be built thus releasing the full potential of an individual. So what should teachers do to establish this kind of harmonious atmosphere for students? The author thinks that the teachers should be sincere, embrace positive regard and be empathy.

\subsection{Treat Students Sincerely and Establish A Good Relationship of Trust with Students.}

In personal relationships, sincerity, the basis for establishing a free and democratic teacher-student relationship, should be placed at first place. Only if the two sides do not show any affectation or hypocrisy can they establish a good relationship with mutual trust. Rogers believed that the learning facilitators could only gain the trust of students by demonstrating true self and then to conduct in-depth communication for a better understanding of students. In the process of education and conversion of the underachievers, teachers must also be sincere and consistent, truly express themselves, and make them feel that teachers can be trusted.

"I like my English teacher most who has a good nature and can understands us. I didn't study English very seriously before. I feel that English classes are not very painful now. Sometimes I also want to seek some advice from my English teachers about something unrelated to studying." (Student $\mathrm{D}$ with learning difficulties)

Sincerity means that both sides need to treat each other frankly, understand each other's thoughts and ideas in the communication and interaction with each other and enhance the understanding and trust in the process of communication. This requires teachers and students to truthfully express their opinions, ideas, and feelings, and teachers should not impose their own opinions and ideas on students. Only when the teacher is sincere towards the students, can the students open up their hearts and may be willing to actively communicate with the teachers. If students do not trust teachers, it is difficult for students to listen to the teacher's persuasion, and it is even less likely that they will actively seek help from teachers when encounter problems.

\subsection{Unconditional Positive Attention to Students for a Comprehensive and Timely Understanding of Them.}

Unconditional positive attention is an active acceptance and support of teachers for students. Teachers should not place themselves in the position of authority, rather they should act as the learning facilitators who should create an atmosphere of "unconditional active regard" and show loving care for students. In the same way, as for the education and conversion of underachiever, teachers should do their best to respect and care for them to help them gain the sense of self-identity and make them feel valued, and further mobilize their potential to achieve self-development in an all-around way.

"When I transferred to Dalian in grade seven, the head teacher gave me a lot of help. I can't adapt to its rice-dominated eating habit there. Therefore, he leaves the only five or six steamed buns distributed by the dinning for every class for me every time to satisfy my habit."(Student B with learning difficulties).

What teachers do as "learning facilitators" are not only lectures. Instead, they need focus on the changes of students and try to explore the causes of learning difficulties for students. If teachers just blindly instill knowledge, it will do little help for some poor students with learning difficulties.

"The teacher talked to me several times just saying that why I work so hard that I can't get a good grade."(Student C with learning difficulties).

"I do particularly poorly in chemistry since in junior high school. Now I can even hardly understand my teacher. My teacher is not very strict. She does not ask questions in class and does not yell at us."(Student $\mathrm{C}$ with learning difficulties).

Unconditional positive regard will improve students' self-esteem and confidence. The unconditional positive regard of teachers shown in the process of student's self-development can 
enable the students to gain a positive sense of self-identity to find a positive motivation from the teacher's attention thus being more confident.

"Last year, one girl in my class ranked the 47th place when she entered school. From the beginning of the school to the mid-term examination, I often talked to her asking her how to learn in junior high school. Then, I told her how she should learn in the high school based on subjects' features. In addition, I gave her some assignments like an English reading comprehension for her poor English score of 30 as well as a math problem, a physics problem every day. Then she got the eighth in final exam. So I think that you have to care for students and make them feel teachers' attention and concerns, and then you have to show respect for them. You must put yourself into their shoes no matter what you do. Whether it is criticism or not, you have to make allowance for them." (Teacher $\mathrm{Du})$

Rogers believed: “There is a basic need asking for others' positive regard (acceptance and support) for a newborn baby. It is this demand that becomes the main force for the socialization of children's behavior."'[6]

"We do not give enough attention as we generally pay attention to the students either with a particular good grades or students that are very naughty. Therefore they often think that the teachers do not pay special attention to them. I would often communicate with every student in our class of the 50 or 60 in the first week or two of the new term so that they can feel my appreciation thinking that they have a place in teacher's mind." (Teacher Du)

"If you give your attention in the beginning, and he still doesn't behave well, then it's OK to put him aside making him feel like he is ignored. When he feels that the teacher no longer cares about him, he may do some changes. He will turn his focus on learning to win your attention." (Teacher Du)

It is a shining indication of students' needs for attention of the teacher. When the teachers change their attentions to others, the neglected student will change themselves and actively seek the attention of the teachers. If teachers do not attach unconditional positive regard to students with learning difficulties, it is more and more difficult for them to improve their academic performance while making students with good grades more and more excellent for more attentions from teachers.

\subsection{Show Empathy and Express Expectations and Confidence in Students.}

It is the best way to make teachers and students more psychologically close to embrace empathy which also acts as a bridge for communication and exchange. This means that teachers should respect students and put themselves in students' shoes to understand what they are thinking about or we can say just showing their empathy, understanding and respect rather than giving a qualitative assessment of students. It requires the teachers to be a good listener for students' opinions knowing how to protect the dignity of the students. Furthermore, teachers are also required to give more encouragements for students who are poor in learning expressing their expectations and confidence. With this kind of encouragement for underachievers, teachers can build a partnership with the students who then are willing to share their inner world with the teacher laying a good foundation for further guidance and transfer of those underachievers.

"We were asked to write something that is the most impressive in junior high school. What I wrote was the kind of topic that teachers did not advocated. I remembered that I liked a girl in our class. She had a very good grade. I worked so hard to catch up with her and I wrote all these down. I thought that my teacher would punish me and gave me a low score. But it turned out I received a surprising praise. The comments said that my writing was full of the expression of true feelings in my heart, and I've done a good job therefore my teacher awarded me a high score."(Student B with learning difficulties).

When students do their tasks, their ability to analyze and solve problems and exploration will be displayed in varying degrees. Therefore, teachers should pay attention to affirming and commending students for their active participation and exploration when making evaluations and then point out objectively and justly where students need improvement. Teachers' encouragement after evaluation is more conducive to students' enthusiasm and motivation.

"What I remember particularly clearly is that the exam a few days ago, my mother said that my academic performance has been declining. My head teacher said to my mother: Do not ask her so 
strict, I believe her! I think these words touched me a lot, because I never thought that my teacher expected so much from me." (Student A with good performance)

"My chemistry teacher encouraged me to tell me that I don't need to care too much about this exam". (student B with learning difficulties)

"At that time, I transferred to the foreign language class of English. I didn't do well in English exam as English was hard to learn. Others in our class had a good English foundation. Each time I counted backwards. Then my teacher, he is also an English teacher encouraged me not to give up, and finally my grades were above the average of the class."(Student B with learning difficulties)

"When communicating, I usually set an expectation for him. I think he can reach a certain height. This expectation encourages him to believe that he can do well. His bad performance emanates from his bad habits. He can surely deliver a good performance if he can develop good habits." (Teacher Du)

When a student is frustrated, it is exactly the moment that his self-confidence is hit harder and weaker. At this time, the teacher's expectation can enhance students' self-confidence and stimulate student morale.

"Students who like to be praised are those clever yet idle one with more assertive personality and would become very impatient for teachers kind nagging. At the beginning, I had no experience. I felt that this kind of student was a relatively poor student. And I often criticized them. Maybe it cannot be criticism by name yet almost of it. But I found that the effect was not very good. This year, there is this kind of girl student in my class. I talked to her several times and praised her saying that she was very clever, and then appointed her as a class cadre. Later on, things became better and better. She became very responsible and sometimes she was able to ascend to the top 10 places in class. My conclusion is that good students are bred in recommendation." (Teacher Du)

Each student's characteristics are different. No one size fits all. The teacher should fully understand the situation of students and teach students in accordance with their aptitude.

"Always praise those poor performers and instill good practices viable in good students into them for guidance. Praise him when he achieved certain progress, and make him continue to do so. Assign the amount of exercises, and lay out the tasks and then I have to check them." (Teacher Du)

"I often recommend inspiring articles in class, both in Chinese and English, just to help them build confidence. I often encourage my high school students as they are really in high pressures. The poorer one are often asked to my office to do dictation practice. At the beginning, I just ask them to dictate simple sentences. I would encourage them for their every progress. And I also introduce my own English learning methods to them." (Teacher Liu)

Rogers attached great importance to the individual's internal emotional factors. In fact, his non-directive teaching is essentially emotional and irrational. Teachers' empathy toward students is a very important emotional factor in non-directive teaching. When students obtain the teacher's expectations and encouragement, it will help enhance students' self-identity and unleash their greater potential.

\subsection{Cultivate the Learning Interest of Students and Urge Them to Study.}

In traditional education field, Rogers believed that "Teachers are the owner of knowledge while student are the passive receiver; the study situation of students can be controlled by teachers through the way of giving the lessons, conducting an examination and even criticizing students. In contrast, there is no way for them to select another learning style. The teacher is the one who casts commands followed by students." From the perspective in education and politics, such kind of education theory can be named "pot and cup". Teachers (pots) have sensible, factual knowledge, and students (cups) are negative containers where knowledge can be poured into them [3]. This kind of spoon-feeding teaching method only allows students to blindly memorize what they learn, but can't inspire their interest in learning. Even worse, it can arouse their repulsion and dislike to learning.

According to the causes of the students with learning difficulties mentioned above, we learn that students with learning difficulties are generally not interested in their own disadvantaged subjects. Teachers should play an active role in guiding students through various teaching methods. 
"She (the Chinese teacher) often talks to me, helps me find some extracurricular books and enlightens me when I am in trouble."(Good student A)

"I like my head teacher most who is very kind to each of us and he checks my learning progress frequently. His class is very interesting because he always tells us some interesting things in daily life. So we are not afraid of him and many students are willing to answer his question in the class."(Good student A)

The above interviews show that students also hope to understand knowledge beyond textbooks. Therefore, teachers can expand students' horizons by providing some extra-curricular books, or interpret complex theorems with examples that are close to life, giving students the opportunity to learning in a significant way.

As for the fact that some students with learning difficulties are prone to laziness, teachers must not only guide students' learning, but also must use appropriate methods to supervise and urge students with learning difficulties.

"I like my biology teacher who lectures his class well. We dare not take a nap in his class because he will hit us if he finds us nod off. I prefer to a serious teacher who even hits me when I do not obey the order. It is an effective way to improve grades."(Student $\mathrm{C}$ with learning difficulties)

"The supervision and urge of students are needed for students as they can't insist on study. This student is one who are willing to take teachers' advice. I don't know his performance at home during the holiday, but he seldom does not complete his homework at school. I usually check their homework once a week."'(Teacher Du)

According to what the student $\mathrm{C}$ says, we can see that some students with learning difficulties know that their self-control is poor and they hope to get the teachers' supervision. Here, the active supervision of teachers is a part of teachers' duty as a facilitator of students to provide students with a good learning atmosphere. Of course, corporal punishment is not feasible. Other forms of supervision, such as asking questions frequently, checking under classes, can be taken by teachers.

"Some students who have a superior family condition believe that study is not important. Generally, I instill in them the hard-work value and urge them to study."(Teacher Liu)

The nature of learning is not grasped by some students with learning difficulties. Under the pressure of the college entrance examination, students just study in a mechanical manner which can be called a utilitarian study without emotional input. That is what Rogers called insignificant learning. The phenomenon described in the above interviews is due to the fact that there is no good motivation to inspire students to achieve self-realization. Therefore, teachers as "facilitators of learning" should guide students to combine their interests and learning. Only students fully immerse themselves into the learning process can they active their learning motivation.

In summary, the "non-directive instruction" proposed by Rogers is an imperative and indicative instruction different from the traditional guidance. It emphasizes that teachers provide a democratic, free learning atmosphere where students can study freely so that they can exert their maximum potential. The core of Rogers' "non-directive instruction" theory is to establish the interpersonal relationship needed for free learning. He believed that the main function of teaching was to form a classroom psychological atmosphere with real, accepted, and understandable features, which made students can freely express themselves, participate freely, and realize their strength and existence in such atmosphere [5].

\section{The Relationship between the Attitude of Students with Learning Difficulties Towards Teachers and the Learning Effectiveness}

The requirement of a good teacher-student relationship is not only that teachers should be sincere, provide unconditional positive attention for students and have empathy, but also students should have a correct attitude towards learning, responsibility for their own learning and be willing to follow the guidance of teachers for striving to improve their learning ability. Therefore, the joint efforts of both 
teachers and students are needed in the development of a teacher-student relationship in a positive and harmonious direction.

"I'm not a kind of students who like studying in fact. My learning attitude is not very correct. Sometimes I also copy others' homework. My teachers spend much time in educating me and I only learn when the teacher supervises me by my side. I, however, can finish all homework assigned by teachers."(Good student A)

"In our class, there is a student who has always got high scores in mathematics exams while he has only got a dozens of points in English exams. This is definitely because that he doesn't work hard in English. I tell him that I would always supervise you and definitely improve your grades. So I start to check his learning progress in a regular time since last conversation. However, the student doesn't insist on it and I have no other way."'(Teacher Liu)

In order to establish a good teacher-student relationship, the good attitude of students toward their teachers is also a necessary factor. Changes in students' emotion can also influence teachers' feeling and thus affect teacher-student relationships. Good students with relatively correct learning attitudes are willing to cooperate with teachers to complete their learning tasks. However, students with learning difficulties often do not complete the task of teachers and are reluctant to give their teachers a positive feedback. In fact, many teachers are willing to communicate with students frequently. However, if students do not correct mistakes in many times or can't fulfill their promises to their teachers, teachers will no longer put their trust in the students, tending to give up them finally. Therefore, students with learning difficulties should actively follow the guidance of teachers and complete the tasks they assign. They can seek self-improvement and development in the good learning environment created by their teachers.

\section{The Difficulties for Teachers in the Transformation Process of Students with Learning Difficulties at the Present Stage}

Theoretically, a series of viewpoints contained in the humanistic theory of Rogers who advocated significant and free learning, including the student-centered education view, is correct and can be used to solve the problem about how to transform these students with difficulties in learning. Therefore, the view of Rogers is worth us to study and discuss. However, it is often impossible to use them well in the education practice under the existing educational resources. Even in the heyday of the humanism ideological trend, the teaching propositions, such as "open schools" and "open classes," have not been truly realized. [3] As a result, teachers have encountered some difficulties in resolving the problem of converting poor students at current stage.

"I also try my best to ask students their learning performance. But there are a total of more than 60 students in the class, and it is impossible to communicate with so many students every week. So, generally, I would call someone who have a slip in their grades after a test to my office and ask his/her performance. However, some children do not obey my orders. I have several talks with them and ask them to do homework. Unfortunately, they still do not have any change. As such, I can't believe them anymore. In addition, I can't pay my attention to one student in case of leaving an unfair impression to other students or teachers. There is also a thing I want to say is that the support from students' parents is essential in our teaching process. Some parents are spoiling their children, buying them mobile phones and giving them too much pocket money, which actually affects students' learning."(Teacher Liu)

"We actually will not talk to students frequently in usual if they do not make mistakes. Generally, we will call them for a talk after an exam is finished or when it is near an exam. You know, they have a heavy academic pressure in usual. Therefore it is difficult for us to communicate with these students at one time."(Teacher $\mathrm{Du}$ )

On the one hand, as the limited energy of teachers, it is impossible for teachers to give students a high-quality teaching when they have to manage so many students. Therefore, the author suggests that small class sizes should be implemented in existing education system. In the case, teachers can try 
their best to pay more attention to students and a more harmonious teacher-student relationship can be established. What's more, student's problems can be found in a timely manner and appropriate assistance can be given by teachers through small class sizes.

On the other hand, it is necessary to strengthen the communication between parents and teachers. As parents do not know much about professional education, they must establish a sincere and trustful relationship with teachers in order to understand the real situation of their children at school. It is conducive to create an environment where can inspire students and arouse their learning potential.

\section{References}

[1]. Lou Lifar. The Attitude of Teachers toward Students is an Important Factor in Successful Education [J]. Youth Diary (education and teaching research), 2012(10):57.

[2]. Han Due. A Perspective of Relationship between Teachers and Students under Rogers' Humanistic Educational Thought [J]. Success (education), 2012(06):191-192.

[3]. Chen Qi \& Liu Rude. Contemporary Educational Psychology [M]. Beijing Normal University Publishing Group, 2007.3:206

[4]. Han Xiao. Study on the Psychological Health of Middle School Students with Learning Difficulties [D]. Henan University, 2013.

[5]. Zhang Xiaoping. Analysis of Rogers' "Non-directive Teaching" Model [J]. Hogan Teachers College Academic Journal, 2006(02):67-68.

[6]. Cu Land \& Li Duping \& Zhu Tianjin. Analysis of Rogers' "Humanism" Theory and the Construction of Good Teacher-student Relationship [J]. Folk Art and Literature, 2012(06):216 